\title{
A Longitudinal Study of Academic Success and Failure in Compulsory Secondary Education and Baccalaureate Students through the Millon Adolescent Clinical Inventory (MACI)
}

\author{
Miguel Ángel Broc \\ Department of Educational Sciences, University of Zaragoza, Zaragoza, Spain \\ Email: mabroc@unizar.es, broc@ieselportillo.com \\ Received 7 July 2015; accepted 28 August 2015; published 1 September 2015 \\ Copyright (C) 2015 by authors and Scientific Research Publishing Inc. \\ This work is licensed under the Creative Commons Attribution International License (CC BY). \\ http://creativecommons.org/licenses/by/4.0/ \\ (c) (i)

\begin{abstract}
Aretrospective longitudinal study of a final sample of 311 Spanish students in compulsory secondary education (CSE) and baccalaureate (BAC) between 1 and 6 years after administration of MACI was conducted by analyzing "a posteriori" if they were able to graduate or not in CSE, as well as some form of baccalaureate. The effects of factors such as grade, sex and graduate/urdergraduate were studied over measured variables by MACI, related with personality traits, the concerns expressed and clinical syndromes. Looking retrospectively if emerging patterns of certain personality variables characterizing students as a function of previous factors, statistically significant variables $(p<0.05)$ that clearly differentiate these types of students are detected based on sex, in fourteen scales scores are higher for women, with predominance of internalizing trend and with a large effect size in variables as body disapproval $(0.81)$ and eating disorders $(0.87)$, and in six scales boys with externalizing trend and a large effect of sex factor on the variable predisposition to delinquency $(0.81)$ as well as between different types of academic performance, especially undergraduate students in scales $2 \mathrm{~A}, 6 \mathrm{~B}, 9, \mathrm{~B}, \mathrm{G}$ and $\mathrm{H}$. Finally, references to clinical intervention techniques and educational community services, in Spain, are proposed.
\end{abstract}

\section{Keywords}

Compulsory Secondary Education/Baccalaureate, Academic Success and Failure, Adolescents, MACI, Millon 


\section{Introduction}

Theodore Millon's contributions to psychopathology, clinical psychology and mental health are well known (Millon, 1986b, 1988, 1990; Millon \& Davis, 1996; Millon \& Grossman, 2006; Millon, Grossman, Meagher, Millon, \& Ramnath, 2004), and although its contribution has focused on the clinical setting, and has enjoyed an international acceptance and validity, his biopsychosocial model has not been excessively exploited in Spain, and we have found few empirical studies analyzing its feasibility and usefulness of this clinical model in educational contexts and students potentially at risk, and their relation to variables such as school performance, academic success and failure, emotional intelligence and others. Our intention is to delve and try to check the usefulness of the model in the educational context, to see if there are personality variables, expressed preoccupations or clinical syndromes that constitute a model or a constellation of associated patterns that characterize certain students in the failure continuum versus academic success, and to see if it can be used for the detection, assessment, intervention or guidance for youngsters in risk of mismatch but have not been detected in the school year or educational stage in which they are enrolled.

In a similar way, Vinet, Salvo \& Forns (2005) conducted a study with non-consulting Chilean adolescents but at risk, using MACI, finding that these are not a homogenous group, and where a susset of risk was detected, reaching about $27 \%$ of subjects, noting that adolescent women showed a level of mental health slightly lower than that of men.

Meanwhile, Vinet \& Forns (2006) conducted a research to determine the ability of MACI to discriminate difference between general population and clinical, obtaining affirmative results to detect cases at risk, and they gave cultural arguments to explain some response tendencies in certain scales by Chilean individuals who took part in that study. These authors reported that the differentiation according to the age group considered (13 - 15 and 16 - 19), and the present in the original study rules of Millon was less clear in non consultants.

Moreover, the use of MACI in community population has allowed the description of troublesome personality styles (Meeker, 2002), has helped to clarify adolescents requiring professional help from those who did not (Casullo, Gongora \& Castro, 1998), has been used with adolescents without mental health problems, in adolescents with clinical syndromes, social adjustment problems and no young consultants (Vinet \& Alarcón, 2003) and for psychological disorders (Vinet \& Santacana, 2008). Perez, Diaz and Vinet (2005) report differences found in many of the scales on the basis of gender, and in a study with Argentine individuals, Casullo and Castro (2002) found differences in 23 of the 27 scales between men and women. It has also been used with "normal" young people involved in sexual offenses (Wasserman, 2001), even to find relationships between certain personality styles and constructs as attachment (Meeker, 2002), or social maladjustment in adolescence (Alarcón, Vinet \& Salvo, 2005).

The design used in this research is of the "ex post facto" type because the independent and dependent variables are related to the subjects, that is, they are already given and have occurred, and therefore, the "pre-existing” variables are studied in individuals or its determinants. Within this typology the present study would be part of what is called retrospective design of only a group. In this sense, Broc \& Gil (2008) found that the scales of family discord, social insensitivity, limit trend, self-punitive, and unruly were MACI variables entering the equation for predicting academic performance in adolescent men of the $4^{\text {th }}$ year of obligatory secondary education (tenth grade), while the Identity Diffusion and Body Disapproval were typical of adolescent women. In high school stage (eleventh and twelfth stage), the best predicting variable was Oppositional in males and Dramatizing in adolescent girls.

Although the theoretical model of Millon and his measure instruments are aimed at people with a specific psychopathology, clinical disorders "per se", would not be possible to extend this instrument samples, allegedly without risk, in order to detect cases, although at one point in their evolutionary process it does not present an exacerbation of their problems: could it be said that they are in a line or clear trend towards mismatch?

The assumptions are detailed below: 1) Due to the difference between the genders, statistically significant differences in MACI subscales, depending on the age and school year will be found; 2) There is a certain parallelism in adolescents between a biopsychosocial mismatch level and academic achievement, so it expects to find a constellation of MACI's variables associated with school failure, and other partners associated to success. In other words, the variables associated with academic failure would go in the direction of the mismatch on the model, while the variables associated with success would head towards the opposite direction, which is adapta- 
tion; 3) Certain variables characterize students differentially as a function of its location in a particular academic category (Undergraduate, graduate in secondary education, and graduate in secondary education and baccalaureate).

The objectives were to: 1) analyze the reliability of the scale in a non-clinical sample of adolescents residing in Spain and within our education system; 2) provide descriptive data of the variables depending on the grade and sex, so that it is used as comparison with other studies; 3) detect whether emerging patterns are consistent of configurations or variables measured through MACI scale in educational contexts associated with students with failure and/or success in the same school, graduating or under graduating in compulsory secondary education, and in high school, analyzing the nature of these differences and the direction among the three types of performance, taking into account the one proposed by Achenbach (1993) on internalization-externalization, and McCann (1999), potentially adolescent offenders - type 1; insecure and troubled teens-type 2; and polarized borderline adolescents-type 3 .

\section{Method}

\subsection{Participants}

The final number of Spanish students who took part in the follow-up years after the application of MACI was 311 with 155 boys, of whose 36 (11.6\%) were undergraduate in compulsory secondary education (CSE), 44 $(14.1 \%)$ were graduate in the same stage and $75(24.1 \%)$ in the same stage and also in baccalaureate; and 156 girls, of whose 35 (11.3\%) were undergraduate, 39 (12.5\%) were graduate in CSE and 82 (26.4\%) were graduate in CSE and also in baccalaureate. The total number of undergraduate students was 71 (22.8\%), the total of graduates in CSE was 83 (26.7\%), and the total number of graduates in CSE and in baccalaureate was 157 (50.5\%). All available data from the school of reference were collected, and used with absolute privacy, being used only for statistical purposes. All participants gave informed consent. From data collection several years after at the same high school, IES "El Portillo" in Zaragoza, it was possible to determine the number of students who graduated or not and at what educational stage. For economic and time reasons, this institute was chosen because the researcher was working in it, and it was not possible to carry it out anywhere else. However, it is a public school where medium or medium low socioeconomic status students attend classes, and is representative of those in Zaragoza in Spain.

\subsection{Variables and Measurement Instruments}

The three factors used were gender, operation alized dichotomously as male $=1$, and female $=2$; the grade, which adopted six values of $1-4$ from $1^{\text {st }}$ to $4^{\text {th }}$ Compulsory Secondary Education (CSE); a code of 5 in eleventh grade, and 6 in second high school; graduated variable, with three values: $1=$ not graduate or under graduate in CSE, 2 = graduated in CSE, and 3 = graduated in CSE and baccalaureate.

The variables were the $27 \mathrm{MACI}$ scales, distributed as follows: 12 personality prototypes: 1-Introverted, 2A-Inhibited, 2B-Doleful, 3-Submissive, 4-Dramatizing, 5-Egotistic, 6A-Unruly, 6B-Rude, 7-Conforming, 8AOppositional, 8B-Self-Demeaning, 9-Borderline Tendency; 8 expressed preoccupations: A-Identity Diffusion, B-Self-Devaluation, C-Body Disapproval, D-Sexual Discomfort, E-Peer Insecurity, F-Social Insensitivity, G-Family Discord, H-Childhood Abuse; and 7 clinical syndromes: AA-Eating Dysfunctions, BB-Substance Abuse Proneness, CC-Delinquent Predisposition, DD-Impulsive Propensity, EE-Anxious Feelings, FF-Depressive Affect, GG-Suicide Tendency (TEA Ediciones, 2004). Because transformations ratings rate-base (TB) is complex and because it is evaluating samples, in principle, notclinics, we chose to work directly with raw or raw scores.

\subsection{Procedure}

Between 1 and 6 years after the administration of MACI to the respective students of the school, the data from their academic dossiers of them were obtained and their graduation or not in the CSE and baccalaureate, through access to confidential data held in the school secretary. Three categories were established by assigning a score of 1 to all students who failed to graduate in compulsory secondary education; the value 2 to students who obtained the certificate of graduation in CSE, but not continued later in high school. And value 3 to those who also finished baccalaureate school, in some of the modalities. This factor was a major one, besides gender and grades, 
being MACI variables considered in principle as dependent variables. Subsequently, data were entered into the data editor SPSS Statistics 21and the corresponding statistical analysis, were executed. The main techniques of data analysis were as follows: Reliability Analysis (Cronbach' alpha), One-way ANOVA for comparison of means in MACI variables according to sex and grade (in this last variable adding Post Hoc comparisons between pairs of groups such as Tukey). Finally, techniques or programs to calculate the effect size, such as Cohen’s d or Hedges's $\boldsymbol{g}$ (Coe, 2002; Coe \& Merino, 2003; Cohen, 1988; Domínguez, 2013).

\section{Results and Discussion}

Regarding the first objective, the reliability analysis of the scale shows very acceptable data, Cronbach $\alpha=0.83$. Tukey's non-additivity test with Anova shows a fully adequate data (between scales, $F=859.96, p<0.00$, and no residual additive, $F=1796,67, p<0.00)$. Hotelling $T^{2}$ test also yields satisfactory results $(61,731.79, F=$ 2233.97, $\left.d f_{1}=26, d f_{2}=398, p<0.00\right)$.

In relation to the second of our goals, some studies have found significant differences in the variables of MACI among younger adolescents (13 - 15 years old) and the most mature, between 16 and 19 years old. Contrary to what might be expected by the theoretical model, in this research we have found almost no statistically significant difference between the 6 groups (4 in CSE and 2 High School-baccalaureate), except in the following scales: 1) 9-Borderline Tendency, reaching the highest score in 2nd CSE, with $M=12.68, S D=9.55$ and $\left(F_{5,419}\right.$ $=2.37, p<0.05)$; 2) D-Body Disapproval, higher in 1st CSE, with $M=33.18, S D=5.54$ and $\left(F_{5,419}=4.43, p<\right.$ $0.001)$; 3) H-Childhood Abuse, higher in 1st CSE, with $M=7.24, S D=7.01$ and $\left(F_{5,419}=2.33, p<0.05\right)$; and finally, GG-Suicidal Tendency, higher in 1st CSE with a $M=8.29, S D=9.17$ and $\left(F_{5,419}=2.37, p<0.05\right)$.

However, the data are very different when considering gender as the main factor on which to base the contrasts of the average scores of the scales considered as dependent variables. Table 1 shows the means and standard

Table 1. Descriptive statistics and comparison of scores between boys and girls in the MACI scales.

\begin{tabular}{|c|c|c|c|c|c|c|c|}
\hline \multirow{2}{*}{\multicolumn{2}{|c|}{ Subscales }} & \multicolumn{2}{|c|}{ Boys } & \multicolumn{2}{|c|}{ Girls } & \multirow[b]{2}{*}{$F$} & \multirow[b]{2}{*}{ Sig. } \\
\hline & & $M$ & $S D$ & $M$ & $S D$ & & \\
\hline 1 & Introverted & 19.46 & 9.33 & 20.94 & 8.73 & 2.85 & 0.09 \\
\hline $2 \mathrm{~A}$ & Inhibited & 16.63 & 9.85 & 20.82 & 10.49 & 17.9 & 0.00 \\
\hline $2 \mathrm{~B}$ & Doleful & 9.54 & 8.29 & 12.45 & 10.09 & 10.5 & 0.00 \\
\hline 3 & Submissive & 45.97 & 9.95 & 50.78 & 8.96 & 27.4 & 0.00 \\
\hline 4 & Dramatizing & 40.59 & 9.12 & 37.39 & 9.31 & 12.7 & 0.00 \\
\hline 5 & Egotistic & 35.75 & 9.10 & 30.19 & 9.38 & 38.3 & 0.00 \\
\hline $6 \mathrm{~A}$ & Unruly & 28.44 & 11.51 & 24.08 & 10.70 & 16.4 & 0.00 \\
\hline $6 \mathrm{~B}$ & Rude & 8.96 & 7.85 & 8.11 & 6.55 & 1.45 & 0.23 \\
\hline 7 & Conforming & 48.53 & 9.46 & 48.69 & 9.36 & .031 & 0.86 \\
\hline $8 \mathrm{~A}$ & Oppositional & 18.84 & 9.55 & 19.52 & 10.20 & .50 & 0.48 \\
\hline $8 \mathrm{~B}$ & Self-Demeaning & 16.90 & 11.83 & 21.05 & 13.88 & 10.9 & 0.00 \\
\hline 9 & Borderline Tendency & 9.85 & 6.35 & 12.70 & 8.82 & 14.3 & 0.00 \\
\hline A & Identity Diffusion & 11.96 & 7.13 & 12.70 & 8.82 & 1.29 & 0.25 \\
\hline B & Self-Devaluation & 15.95 & 12.01 & 22.89 & 13.94 & 29.9 & 0.00 \\
\hline $\mathrm{C}$ & Body Disapproval & 6.56 & 6.33 & 13.01 & 9.29 & 68.7 & 0.00 \\
\hline $\mathrm{D}$ & Sexual Discomfort & 27.88 & 6.25 & 31.03 & 6.22 & 27.0 & 0.00 \\
\hline $\mathrm{E}$ & Peer Insecurity & 8.36 & 4.75 & 8.75 & 5.08 & .67 & 0.41 \\
\hline $\mathrm{F}$ & Social Insensitivity & 25.53 & 8.56 & 20.10 & 7.08 & 50.9 & 0.00 \\
\hline G & Family Discord & 13.08 & 5.73 & 14.59 & 6.82 & 5.99 & 0.01 \\
\hline $\mathrm{H}$ & Childhood Abuse & 4.97 & 4.58 & 6.30 & 5.37 & 7.52 & 0.00 \\
\hline AA & Eating Dysfunctions & 6.45 & 6.76 & 14.33 & 10.84 & 79.3 & 0.00 \\
\hline $\mathrm{BB}$ & Substance Abuse Proneness & 14.84 & 10.90 & 12.49 & 9.91 & 5.40 & 0.02 \\
\hline $\mathrm{CC}$ & Delinquent Predisposition & 24.62 & 7.43 & 19.12 & 6.10 & 69.6 & 0.00 \\
\hline DD & Impulsive Propensity & 13.79 & 6.37 & 13.07 & 6.82 & 1.28 & 0.25 \\
\hline $\mathrm{EE}$ & Anxious Feelings & 29.58 & 6.96 & 33.10 & 6.79 & 27.7 & 0.00 \\
\hline $\mathrm{FF}$ & Depressive Affect & 12.55 & 8.69 & 18.69 & 11.11 & 39.8 & 0.00 \\
\hline GG & Suicidal Tendency & 5.39 & 6.31 & 8.20 & 8.37 & 15.0 & 0.00 \\
\hline
\end{tabular}


deviations of boys and girls in all variables in the MACI, and the significance of the differences is presented. Levene's test of homogeneity of variance confirmed that the mean scores on the scales by gender come from different populations.

According to the previous table teenage girls obtained higher scores than boys, statistically significant $(p<$ 0.05) at scales 2A, 2B, 3, 8B, 9, B, C, D, G, H, AA, EE, FF and GG, while boys reach higher scores on the variables 4, 5, 6A, F, BB and CC. No significant differences between the sexes to 1, 6B, 7, 8A, A, E and DD are detected, so that we can say that girls score higher in 14 scales, boys in 6, and no differences in 7 of the 27 MACI scales. Could we then conclude that teenage girls are more likely than boys to develop maladaptive patterns? In principle, these scores are not included within the threshold of psychopathology, because the study was not conducted with clinical analogs or with teenagers in psychological or psychiatric treatment, or in detention and, therefore, it is a "non-consultant sample" but we could suggest a higher initial bias toward adolescent psychopathology in the sample girls. The effect size is shown in Table 2.

Vinet et al. (2005: p. 94), from the work of McCann (1999) on the grouping of scales and the internalization versus outsourcing model proposed by Achenbach $(1991,1993)$ provides a typology that matches our research, with boys within the framework of the study of these authors: McCann (1999) proposed that the setting " 4 - 5" or "5 - 4" Dramatizing and Egotistic is characteristic of adolescents with narcissistic traits and self-centered behaviors

Table 2. Effect' size and indexes observed in MACI's scales of the sex factor.

\begin{tabular}{|c|c|c|c|c|c|c|c|}
\hline & $\begin{array}{c}\text { Mean } \\
\text { Difference }\end{array}$ & $\begin{array}{l}\text { p-value for mean } \\
\text { diff (2-tailded T-test) }\end{array}$ & $\begin{array}{l}\text { Effect } \\
\text { Size }\end{array}$ & $\begin{array}{c}\text { Bias } \\
\text { corrected } \\
\text { (d Cohen) }\end{array}$ & $\begin{array}{l}\text { Standard Error } \\
\text { of E.S. estimate }\end{array}$ & $\begin{array}{l}\text { Confidence Interval } \\
\text { for Effect Size Lower }\end{array}$ & Upper \\
\hline 1Introverted & 1.48 & 0.15 & 0.16 & 0.16 & 0.11 & -0.06 & 0.39 \\
\hline 2A Inhibited & 4.19 & 0.00 & 0.41 & 0.41 & 0.11 & 0.19 & 0.64 \\
\hline 2B Doleful & 2.91 & 0.01 & 0.32 & 0.31 & 0.11 & 0.09 & 0.54 \\
\hline 3 Submissive & 4.81 & 0.00 & 0.51 & 0.51 & 0.12 & 0.28 & 0.73 \\
\hline 4 Dramatizing & 3.20 & 0.00 & 0.35 & 0.35 & 0.11 & 0.12 & 0.57 \\
\hline 5 Egotistic & 5.56 & 0.00 & 0.60 & 0.60 & 0.12 & 0.37 & 0.83 \\
\hline 6A Unruly & 4.36 & 0.00 & 0.39 & 0.39 & 0.11 & 0.17 & 0.62 \\
\hline 6B Rude & 0.85 & 0.30 & 0.12 & 0.12 & 0.11 & -0.11 & 0.34 \\
\hline 7 Conforming & 0.16 & 0.88 & 0.02 & 0.02 & 0.11 & -0.21 & 0.24 \\
\hline 8A Oppositional & 0.68 & 0.54 & 0.07 & 0.07 & 0.11 & -0.15 & 0.29 \\
\hline 8B Self-Demeaning & 4.15 & 0.00 & 0.32 & 0.32 & 0.11 & 0.10 & 0.54 \\
\hline 9 Borderline Tendency & 2.85 & 0.00 & 0.37 & 0.37 & 0.11 & 0.15 & 0.59 \\
\hline A Identity Diffusion & 0.74 & 0.42 & 0.09 & 0.09 & 0.11 & -0.13 & 0.31 \\
\hline B Self- Devaluation & 6.94 & 0.00 & 0.53 & 0.53 & 0.11 & 0.31 & 0.76 \\
\hline C Body Disapproval & 6.45 & 0.00 & 0.81 & 0.81 & 0.12 & 0.58 & 1.04 \\
\hline D Sexual Discomfort & 3.15 & 0.00 & 0.51 & 0.50 & 0.12 & 0.28 & 0.73 \\
\hline E Peer Insegurity & 0.39 & 0.48 & 0.08 & 0.08 & 0.11 & -0.14 & 0.30 \\
\hline F Social Insensivity & 5.43 & 0.00 & 0.69 & 0.69 & 0.12 & 0.46 & 0.92 \\
\hline G Family discord & 1.51 & 0.04 & 0.24 & 0.24 & 0.11 & 0.02 & 0.46 \\
\hline H Childhood Abuse & 1.33 & 0.02 & 0.27 & 0.27 & 0.11 & 0.04 & 0.49 \\
\hline AA Eating Dysfunctions & 7.88 & 0.00 & 0.87 & 0.87 & 0.12 & 0.64 & 1.10 \\
\hline BB Substance Abuse & 2.35 & 0.05 & 0.23 & 0.23 & 0.11 & 0.00 & 0.45 \\
\hline CC Delinquent Predisposition & 5.50 & 0.00 & 0.81 & 0.81 & 0.12 & 0.58 & 1.04 \\
\hline DD Impulsive Propensity & 0.72 & 0.34 & 0.11 & 0.11 & 0.11 & -0.11 & 0.33 \\
\hline EE Anxious Feelings & 3.52 & 0.00 & 0.51 & 0.51 & 0.12 & 0.28 & 0.74 \\
\hline FF Depressive Affect & 6.14 & 0.00 & 0.62 & 0.61 & 0.12 & 0.39 & 0.84 \\
\hline GG Suicidal Tendency & 2.81 & 0.00 & 0.38 & 0.38 & 0.11 & 0.15 & 0.60 \\
\hline
\end{tabular}


and attitudes, associated with an increased need for stimulation and difficulty delaying gratification. This configuration is associated, also in this research, to social insensitivity and predisposition to delinquency and relative indifference to the reactions and feelings of others and the difficulty to adhere to the rules and social norms, being this group of teenagers potential offenders and those at risk of externalizing disorders, in the line proposed by Achenbach (1993) also adding rebellion and substance abuse.

The second typology proposed by McCann (1999) and the group at risk for internalizing disorders of Achenbach (1993), we find more approximate, in this work, in adolescent females. The main axis patterns constitute the 3-Submissive and 7-Conformist, which together with increased anxiety, problems with sexuality, and relationships with peers, and so on, leads to a kind of fearful, worried and insecure teenager. In this study, both the conformist scale and insecurity with peers no significant differences between the genders are detected, although adolescent girls scored higher than boys in the rest of the scales proposed as type 2 and internalizing cited by the previous authors.

The third bipolar type is not clearly observed by gender in this particular section, since the dimension of internalization (devaluation of herself and depressive affect) women obtain higher scores, which confirms once again the prevalence of internalizing pattern in women, being less clear the other end of the dimension, the externalizing, composed of rebellion (which scores are higher in the boys) and a tendency toward impulsivity scale in which no statistically significant differences between the genders are detected. This third bipolar type is shown more clearly in the category of "non-graduated”, discussed below.

Regarding the third and fourth goals, and considering the main factor variable "Graduate versus Undergraduate”, divided into three main categories, analyzes reveal potentially relevant configurations which are discussed below. In 13 of the 27 scales (almost 50\%), significant differences in mean scores of MACI emerge in the three groups. Only the scales in which the differences are statistically significant are showed. The number of students in Category 1 = "no graduate or undergraduate" is 71, in category 2 = "graduate students in CSE" is 83, and Category 3 = "graduate students in Secondary Education and Baccalaureate" is 157.

Although no statistically significant differences are detected in the frequencies or percentages of non-graduated, graduated in CSE, and graduated in CSE and baccalaureate by gender, that is, the percentage of adolescent men and women who are graduated or not graduating is similar (Phi, Cramer's $V$, and contingency coefficient $=$ 0.045, are approximate significance of 0.73 , which the null hypothesis is accepted), if we forget the gender factor and move to the Graduation factor, we think it is possible to see a pattern of variables that could coexist and be unique to each category including here both men and women. Regarding this, significant differences were detected between the three categories of students, according to Table 3, in 13 of the 27 scales. It is necessary to stop at this observation because of the difficulty to explain all the differences between these three groups (Tukey technique), but could be gleaned some interesting patterns:

1) Students placed in the category of "Undergraduate" obtained higher scores than students in the other two categories on the scales 2A-Inhibited, 6B-Rude, 9-Borderline Tendency, B-Self-Devaluation, and G-Family Discord; 2) Students placed in the categories of "Undergraduate" and "Graduate in Secondary Education" scored higher and statistically more significant than the classmates of the category "Graduated SE and Baccalaureate”, on the scales: 1-Introverted, 2B-Doleful, 8A-Oppositional, 8B-Self-Devaluation, A-Identity Diffusion, FF-Depressive Affect, and GG-Suicidal Tendency; 3) In the H-Childhood Abuse scale, the group of "Undergraduate" got higher and more significant scores than the other two groups together, since these latter two did not differ two to two.

These results confirm roughly that the profile of adolescents at risk matches the profile of students undergraduate in CSE, which show very high scores on scales Introverted, Inhibited, Unruly, Rude, Oppositional, SelfDevaluation and Borderline Tendency, concerns raised except those relating to sexuality, and elevations in all clinical syndromes except anxiety. As in the work of Vinet et al. (2005: p. 94), where the anxiety variable does not seem to discriminate, which has led some researchers to rethink the clinical utility of this scale, in this work it is also a variable that doesn't discriminate among the three types of academic performance.

Considering principally the work of Cohen (1988) and Coe (2002), based on the observation data of Table 2 and Table 4, it can be said, in general, the size the effect of the Gender factor is great on the scales $\mathrm{C}$, AA and CC, medium in 2A, 2B, 3, 4, 5, 6A, 8B, 9, B, D, F, EE, FF, GG scales and small or irrelevant in the rest.

Regarding to factor Not Graduation/Graduation this is medium, especially in comparison groups 1 and/or 2 with 3, in the following scales: 1, 2A, 2B, 6B, 8A, 8B, 9, A, B, G, H, FF and GG.

Precisely in the middle of the bipolar category internalization-externalization referred by Vinet et al. (2005), 
the Borderline and Suicidal Tendency scales appear, corresponding to the theoretical model with a dysfunctional and emotionally ambivalent maladaptive pattern to define conflicts in the three dimensions that define Millon's

Table 3. Descriptive statistics and comparison of the MACI's scales according to three categories of students concerning the undergraduate and graduate in compulsory secondary education and baccalaureate.

\begin{tabular}{|c|c|c|c|c|c|c|}
\hline Scales & Categories & $M$ & $S D$ & $F_{(2,308)}$ & Sig. & Post-Hoc (Tukey) \\
\hline & 1-Undergraduate & 22.68 & 9.88 & & & \\
\hline \multirow[t]{3}{*}{ 1-Introverted } & 2-Graduate SE & 22.49 & 10.57 & 7.7 & 0.00 & $(1 \mathrm{y} 2)>3$ \\
\hline & 3-Graduate SE and Bac. & 18.42 & 8.33 & & & \\
\hline & 1-Undergraduate & 21.65 & 12.51 & & & \\
\hline \multirow[t]{3}{*}{ 2A-Inhibited } & 2-Graduate SE & 20.13 & 10.96 & 3.5 & 0.03 & $1>2>3$ \\
\hline & 3-Graduate SE and Bac. & 17.69 & 10.24 & & & \\
\hline & 1-Undergraduate & 15.28 & 11.08 & & & \\
\hline \multirow[t]{3}{*}{ 2B-Doleful } & 2-Graduate SE & 13.41 & 10.17 & 12 & 0.00 & $(1 \mathrm{y} 2)>3$ \\
\hline & 3-Graduate SE and Bac. & 9.23 & 8.38 & & & \\
\hline & 1-Undergraduate & 10.59 & 9.16 & & & \\
\hline \multirow[t]{3}{*}{ 6B-Rude } & 2-Graduate SE & 8.92 & 8.19 & 4.2 & 0.01 & $1>2>3$ \\
\hline & 3-Graduate SE and Bac. & 7.50 & 6.22 & & & \\
\hline & 1-Undergraduate & 23.65 & 11.44 & & & \\
\hline \multirow[t]{3}{*}{ 8A-Oppositional } & 2-Graduate SE & 21.28 & 9.96 & 11 & 0.00 & $(1 \mathrm{y} 2)>3$ \\
\hline & 3-Graduate SE and Bac. & 17.45 & 9.08 & & & \\
\hline & 1-Undergraduate & 23.42 & 14.58 & & & \\
\hline \multirow[t]{3}{*}{ 8B-Self-Demeaning } & 2-Graduate SE & 21.80 & 14.03 & 6.9 & 0.00 & $(1 \mathrm{y} 2)>3$ \\
\hline & 3-Graduate SE and Bac. & 16.98 & 12.62 & & & \\
\hline & 1-Undergraduate & 13.54 & 8.73 & & & \\
\hline \multirow[t]{3}{*}{ 9-Borderline Tendency } & 2-Graduate SE & 12.80 & 8.37 & 5.3 & 0.00 & $1>2>3$ \\
\hline & 3-Graduate SE and Bac. & 10.34 & 6.79 & & & \\
\hline & 1-Undergraduate & 14.66 & 8.71 & & & \\
\hline \multirow[t]{3}{*}{ A-Identity Diffusion } & 2-Graduate SE & 14.01 & 7.99 & 6.4 & 0.00 & $(1 \mathrm{y} 2)>3$ \\
\hline & 3-Graduate SE and Bac. & 11.25 & 6.84 & & & \\
\hline & 1-Undergraduate & 23.27 & 15.26 & & & \\
\hline \multirow[t]{3}{*}{ B-Self-Devaluation } & 2-Graduate SE & 22.17 & 14.18 & 4.5 & 0.01 & $1>2>3$ \\
\hline & 3-Graduate SE and Bac. & 17.99 & 13.16 & & & \\
\hline & 1-Undergraduate & 16.42 & 7.37 & & & \\
\hline \multirow[t]{3}{*}{ G-Family Discord } & 2-Graduate SE & 14.01 & 6.24 & 5.8 & 0.00 & $1>2>3$ \\
\hline & 3-Graduate SE and Bac. & 13.29 & 6.13 & & & \\
\hline & 1-Undergraduate & 8.41 & 6.51 & & & \\
\hline \multirow[t]{3}{*}{ H-Childhood Abuse } & 2-Graduate SE & 6.34 & 4.47 & 12 & 0.00 & $1>(2 y 3)$ \\
\hline & 3-Graduate SE and Bac. & 4.87 & 4.84 & & & \\
\hline & 1-Undergraduate & 18.96 & 12.88 & & & \\
\hline \multirow[t]{3}{*}{ FF-Depressive Affect } & 2-Graduate SE & 18.20 & 11.64 & 6.1 & 0.00 & $(1 \mathrm{y} 2)>3$ \\
\hline & 3-Graduate SE and Bac. & 14.27 & 9.38 & & & \\
\hline & 1-Undergraduate & 10.55 & 10.25 & & & \\
\hline \multirow[t]{2}{*}{ GG-Suicidal Tendency } & 2-Graduate SE & 8.45 & 8.13 & 11 & 0.00 & $(1 \mathrm{y} 2)>3$ \\
\hline & 3-Graduate SE and Bac. & 5.45 & 6.22 & & & \\
\hline
\end{tabular}


Table 4. Effect' size and indexes observed in MACI's scales of the undergraduate/graduate factor.

\begin{tabular}{|c|c|c|c|c|c|c|c|}
\hline $\begin{array}{l}\text { Scales and } \\
\text { groups( }\left(^{*}\right)\end{array}$ & $\begin{array}{c}\text { Mean } \\
\text { Difference }\end{array}$ & $\begin{array}{l}\text { p-value for mean diff } \\
\text { (2-tailded T-test) }\end{array}$ & $\begin{array}{l}\text { Effect } \\
\text { Size }\end{array}$ & $\begin{array}{l}\text { Bias corrected } \\
\text { (d Cohen) }\end{array}$ & $\begin{array}{l}\text { Standard Error of } \\
\text { E.S. estimate }\end{array}$ & $\begin{array}{l}\text { Confidence Interval for } \\
\text { Effect Size Lower }\end{array}$ & Upper \\
\hline $1 \mathrm{G} 1-2$ & 0.19 & 0.91 & 0.02 & 0.02 & 0.16 & -0.30 & 0.34 \\
\hline $1 \mathrm{G} 1-3$ & 4.26 & 0.00 & 0.48 & 0.48 & 0.14 & 0.20 & 0.76 \\
\hline $1 \mathrm{G} 2-3$ & 4.07 & 0.00 & 0.44 & 0.44 & 0.14 & 0.17 & 0.71 \\
\hline 2A G1-2 & 1.52 & 0.42 & 0.13 & 0.13 & 0.16 & -0.19 & 0.45 \\
\hline 2A G1-3 & 3.96 & 0.01 & 0.36 & 0.36 & 0.14 & 0.08 & 0.64 \\
\hline 2A G2-3 & 2.44 & 0.09 & 0.23 & 0.23 & 0.14 & -0.04 & 0.50 \\
\hline 2B G1-2 & 1.87 & 0.28 & 0.18 & 0.18 & 0.16 & -0.14 & 0.49 \\
\hline 2B G1-3 & 6.05 & 0.00 & 0.65 & 0.65 & 0.15 & 0.36 & 0.93 \\
\hline 2B G2-3 & 4.18 & 0.00 & 0.46 & 0.46 & 0.14 & 0.19 & 0.73 \\
\hline 6B G1-2 & 1.67 & 0.23 & 0.19 & 0.19 & 0.16 & -0.13 & 0.51 \\
\hline 6B G1-3 & 3.09 & 0.00 & 0.43 & 0.42 & 0.14 & 0.14 & 0.71 \\
\hline 6B G2-3 & 1.42 & 0.13 & 0.20 & 0.20 & 0.14 & -0.06 & 0.47 \\
\hline 8A G1-2 & 2.37 & 0.17 & 0.22 & 0.22 & 0.16 & -0.10 & 0.54 \\
\hline 8A G1-3 & 6.2 & 0.00 & 0.63 & 0.63 & 0.15 & 0.34 & 0.91 \\
\hline 8A G2-3 & 3.83 & 0.00 & 0.41 & 0.41 & 0.14 & 0.14 & 0.67 \\
\hline 8B G1-2 & 1.62 & 0.48 & 0.11 & 0.11 & 0.16 & -0.20 & 0.43 \\
\hline 8B G1-3 & 6.44 & 0.00 & 0.49 & 0.48 & 0.14 & 0.20 & 0.77 \\
\hline 8B G2-3 & 4.82 & 0.01 & 0.37 & 0.37 & 0.14 & 0.10 & 0.63 \\
\hline 9 G1-2 & 0.74 & 0.59 & 0.09 & 0.09 & 0.16 & -0.23 & 0.40 \\
\hline 9 G1-3 & 3.20 & 0.00 & 0.43 & 0.43 & 0.14 & 0.15 & 0.71 \\
\hline 9 G2-3 & 2.46 & 0.01 & 0.33 & 0.33 & 0.14 & 0.06 & 0.60 \\
\hline A G1-2 & 0.65 & 0.63 & 0.08 & 0.08 & 0.16 & -0.24 & 0.39 \\
\hline A G1-3 & 3.41 & 0.00 & 0.46 & 0.45 & 0.14 & 0.17 & 0.74 \\
\hline A G2-3 & 2.76 & 0.01 & 0.38 & 0.38 & 0.14 & 0.11 & 0.65 \\
\hline B G1-2 & 1.10 & 0.64 & 0.07 & 0.07 & 0.16 & -0.24 & 0.39 \\
\hline B G1-3 & 5.28 & 0.01 & 0.38 & 0.38 & 0.14 & 0.10 & 0.66 \\
\hline B G2-3 & 4.18 & 0.02 & 0.31 & 0.31 & 0.14 & 0.04 & 0.58 \\
\hline G G1-1 & 2.41 & 0.03 & 0.36 & 0.35 & 0.16 & 0.03 & 0.67 \\
\hline G G1-3 & 3.13 & 0.00 & 0.48 & 0.48 & 0.14 & 0.19 & 0.76 \\
\hline G G2-3 & 0.72 & 0.39 & 0.12 & 0.12 & 0.14 & -0.15 & 0.38 \\
\hline H G1-2 & 2.07 & 0.02 & 0.38 & 0.37 & 0.16 & 0.05 & 0.69 \\
\hline H G1-3 & 3.54 & 0.00 & 0.65 & 0.65 & 0.15 & 0.37 & 0.94 \\
\hline H G2-3 & 1.47 & 0.02 & 0.31 & 0.31 & 0.14 & 0.04 & 0.58 \\
\hline FF G1-2 & 0.76 & 0.70 & 0.06 & 0.06 & 0.16 & -0.26 & 0.38 \\
\hline FF G1-3 & 4.69 & 0.00 & 0.44 & 0.44 & 0.14 & 0.16 & 0.72 \\
\hline FF G2-3 & 3.93 & 0.00 & 0.38 & 0.38 & 0.14 & 0.12 & 0.65 \\
\hline GG G1-2 & 2.10 & 0.16 & 0.23 & 0.23 & 0.16 & -0.09 & 0.55 \\
\hline GG G1-3 & 5.10 & 0.00 & 0.66 & 0.66 & 0.15 & 0.37 & 0.95 \\
\hline GG G2-3 & 3.00 & 0.00 & 0.43 & 0.43 & 0.14 & 0.16 & 0.70 \\
\hline
\end{tabular}

(*) Group 1: undergraduate, $n=71$; Group 2: graduate in CSE, $n=83$; Group 3: graduate in CSE and Baccalaureate, $n=157$. 
personality model, namely: the dimensions pleasure-pain, activity-passivity, self-other. In this research, those two scales precisely have higher mean scores and statistically significant in the group of undergraduate in relation to the other two.

\section{Conclusions}

In the present study it is found that MACI is an instrument with a very healthy reliability and, with proper precautions, can be used with teenagers in not necessarily clinical settings, as it has been usual. Furthermore, this instrument is very sensitive to gender differences, because in the three assessed areas, responses and patterns that emerge are quite different between male and female adolescents. Coinciding with Vinet et al. (2005) MACI could extend its use to non-clinical populations, being useful as a descriptive and a screening instrument, especially in the diagnosis of cases at risk (pp. 96), adding from this work, which can be equally applied in educational secondary schools, serving both as a tool for detection of students who may become short-term risk subjects, as for features more associated with a pattern of school failure, and thus serve also as a means of prevention and counseling or psychological and pedagogical short and medium-term intervention. It is also confirmed that the results obtained in the three categories show different patterns that are associated significantly with groups of students with different levels of achievement and point to a maladaptive direction in line with the typologies proposed by McCann (1999) and Achenbach (1991), which give greater external validity.

The treatment or addressing of many of the students who fail to finish secondary education and present problems and personality disorders is not easy from clinical or psycho-pedagogical perspectives, as it requires advanced specialized training in psychology and/or psychiatry, and also one specific training in this case, which is proposed by Millon's model. Moreover, it is not possible to conduct general intervention programs, but an individualized approach, based on the necessary general model, adapted to the idiosyncrasies of each adolescent in a comprehensive way (Cardenal, Sanchez \& Ortiz, 2007). In a similar vein, López, Rondon, Alfaro and Cellerino (2010), have provided a schematic guide treatment of personality disorders for professionals from the Millon's model that can be very useful for those professionals who are interested in this approach. Within the school context, it is recommended in some cases to send these youngsters to community mental health services, or to qualified professionals in the public or private sector.

The issue related to dissatisfaction with one's body in adolescent girls, much higher than males manifest, is still researched from other evolutionary and related mental health and adolescent psychopathology theoretical perspectives in different dimensions of personality, especially in the field of self-concept and global self-esteem. In this line, Harter (2012) has provided interesting interpretations on the latter dimension, which seems to show, in the vast majority of empirical studies, the highest correlations with self-worth in all evolutionary periods, and has been shown by other studies as performed recently by Broc (2014).

This is not the place to discuss the complex therapeutic approach to this subject, but it's stated that mainly both, cognitive behavioral therapy (Beck, Davis \& Freeman, 2014; Fox, 2013; McCann, 1999; Millon, Krueger \& Simonsen, 2010), and the so-called “third generation therapies” as the functional analytic psychotherapy, behavioral activation therapy, dialectical behavior therapy and acceptance and commitment therapy, among others, could be suitable to treat many aspects and facets of these problems with adolescents.

The educational response that can be given to this type of undergraduate students with low academic performance and emerging behavioral problems is equally difficult in our country, although there are some alternatives that have had a positive effect on the normalization of these students who could be estimated by about $70 \%$. In Aragon (Spain), for example, there is the Specific Educational Intervention Units (SEIU), which allows a relative exit for these difficult students and establishes measures of educational intervention for those in personal, social or cultural disadvantaged situations or showing serious difficulties in school adjustment. Another of the existing measures that has shown satisfactory results is the Extraordinary External Schooling for students of 14 and 15 years old, with serious adjustment problems and school failure, in collaboration with the so called SocialWork Centers, dependent on local councils, with the assistance of Department of Education (Aragon Govern) and the technical support by Guidance Departments at institutes.

Finally, another measure of acting and educational attention in our country is the regulation of Basic Professional Formation for those students between 15 and 17 years old that have not successfully completed compulsory secondary education and directed to those students who have been classified as non-graduated, analyzed in this research. 


\section{References}

Achenbach, T. M. (1991). Manual for the Youth Self-Report and 1991 Profile. Burlington: University of Vermont, Department of Psychiatry.

Achenbach, T. M. (1993). Empirically Based Taxonomy: How to Use Syndromes and Profile Types Derived from the CBCL/4-18, TRF and YSR. Burlington: University of Vermont, Department of Psychiatry.

Alarcón, P., Vinet, E., \& Salvo, S. (2005). Estilos de personalidad y desadaptación social durante la adolescencia (Personality Styles and Adjustment Problems in Adolescence). Psykhe, 14, 3-16. http://dx.doi.org/10.4067/S0718-22282005000100001

Beck, A. T., Davis, D. D., \& Freeman, A. (2014). Cognitive Therapy of Personality Disorders (3rd ed.). New York: The Guilford Press.

Broc, M. A. (2014). Harter's Self-Perception Profile for Children: An adaptation and validation of the Spanish Version. Psychological Reports, 115, 444-466. http://dx.doi.org/10.2466/08.07.PR0.115c22z5

Broc, M. A., \& Gil, C. (2008). Predicción del rendimiento académico en alumnos de ESO y Bachillerato mediante el Inventario Clínico para Adolescentes de Millon (escala MACI) (Prediction of Academic Achievement in Obligatory Compulsory Education and Baccalaureate Students through the Millon Adolescent Clinical Inventory). Anales de Psicología, 24, 158-167. https://digitum.um.es/xmlui/handle/10201/8141 http://hdl.handle.net/10201/8141

Cardenal, V., Sánchez, M. P., \& Ortiz-Tallo, M. (2007). Los trastornos de personalidad según el modelo de Millon: una propuesta integradora (Personality Disorders According to Millon’s Personality Model: An Integrative Approach). Clínica y Salud, 18, 305-324. http://scielo.isciii.es/pdf/clinsa/v18n3/v18n3a04.pdf

Casullo, M. M., \& Castro, A. (2002). Patrones de personalidad, síndromes clínicos y bienestar psicológico en adolescentes (Personality Patterns, Clinical Syndromes and Psychological Well-Being among Adolescents). Revista de Psicopatologíay Psicología Clínica, 7, 129-140. http://dx.doi.org/10.5944/rppc.vol.7.num.2.2002.3927 http://revistas.uned.es/index.php/RPPC/article/view/3927/3782

Casullo, M. M., Góngora, V., \& Castro, A. (1998). La adaptación del Inventario MACI (MillonAdolescentClinicalInventory). Un estudio preliminar con estudiantes adolescentes argentinos (MACI Inventory Adaptation. A Preliminary Study with Argentine Adolescent Students). Investigaciones en Psicología, 3, 73-89.

Coe, R. (2002). It's the Effect Size, Stupid. What Effect Size Is and Why It Is Important. Paper Presented at the British Educational Research Association Annual Conference, Exeter, 12-14 September 2002. http://www.leeds.ac.uk/educol/documents/00002182.htm

Coe, R., \& Merino, C. (2003). Magnitud del efecto. Una guía para investigadores y usuarios. Revista de Psicología—PUCP, 21, 147-177.

Cohen, J. (1988). Statistical Power Analysis for the Behavioral Sciences (2nd ed.). New York: Academic Press.

Domínguez, L. S. A. (2013). Tamaño del Efecto: Cálculo mediante un módulo en Visual Basic (Effect Size: Calculation Using a Visual Basic Module). Revista IIPSI, 16, 235-240.

Fox, D. J. (2013). The Clinician's Guide to the Diagnosis and Treatment of Personality Disorders. Eau Claire: PESI Publishing \& Media.

Harter, S. (2012). The Construction of the Self: Developmental and Sociocultural Foundations (2nd ed.). New York \& London: The Guilford Press. http://www.guilford.com

López, A. F., Rondon, J. M., Alfaro, S. M., \& Cellerino, C. (2010). Guías esquematizadas de tratamiento de los trastornos de personalidad para profesionales, desde el modelo de Theodore Millon (Guidelines Sketched for Treatment of Personality Disorders for Professionals from the Millon Perspective). Ciencias Psicológicas, 4, 239-274.

McCann, J. (1999). Assessing Adolescents with the MACI: Using the Millon Adolescent Clinical Inventory. New York: Wiley \& Sons.

Meeker, L. (2002). Adolescent Attachment and Prediction of Problematic Personality Stiles. Dissertation Abstracts International: Section B: The Sciences and Engineering, 63, 2595.

Millon, T. (1986b). Personality Prototypes and Their Diagnostic Criteria. In T. Millon, \& G. Klerman (Eds.), Contemporary Directions in Psychopatology: Toward the DSM-IV (pp. 671-712). New York: Guilford.

Millon, T. (1988). Personologic Psychotherapy: Ten Commandments for a Posteclectic Approach to Integrative Treatment. Psychotherapy, 25, 209-219. http://dx.doi.org/10.1037/h0085335

Millon, T. (1990). Toward a New Personology: An Evolutionary Model. New York: Wiley.

Millon, T., \& Davis, R. D. (1996). Disorders of Personality: DSM-IV and Beyond (2nd ed.). Oxford: John Wiley \& Sons.

Millon, T., \& Grossman, S. D. (2006). Goals of a Theory of Personality. In J. C. Thomas, D. L. Segal, \& M. Hersen (Eds.), Comprehensive Handbook of Personality and Psychopathology, Volume 1: Personality and Everyday Functioning (pp. 3-22). Hoboken, NJ: John Wiley \& Sons Inc. 
Millon, T., Grossman, S. D., Meagher, S., Millon, C., \& Ramnath, R. (2004). Personality Disorders in Modern Life. New York: Wiley.

Millon, T., Krueger, R. F., \& Simonsen, E. (2010). Contemporary Directions in Psychopatology: Scientific Foundations of the DSM-V and ICD-11 (Hardcover). New York: The Guilford Press.

Pérez, M. V., Díaz, A., \& Vinet, E. (2005). Características psicológicas de adolescentes pertenecientes a comunidades educativas vulnerables (Psychological Characteristics of Adolescents Belonging to Vulnerable Educational Communities). Psicothema, 17, 37-42. http://www.unioviedo.net/reunido/index.php/PST/article/view/8287/8151

TEA Ediciones (2004). MACI Inventario Clínico para Adolescentes de Millon Manual (MACI Manual: Millon Adolescent Clinical Inventory). Madrid: NCS Pearson.

Vinet, E., \& Alarcón, P. (2003). El Inventario Clínico para Adolescentes de Millon (MACI) en la Evaluación de Adolescentes Chilenos (The Millon Adolescents Clinical Inventory in the Assessment of Chilean Adolescents). Psykhe, 12, 39-55. http://www.psykhe.cl/index.php/psykhe/article/view/346/326

Vinet, E. V., \& Forns, M. (2006). El Inventario Clínico Para Adolescentes de Millon (MACI) y su Capacidad Para Discriminar Entre Población General y Clínica (Millon’s Adolescent Clinical Inventory (MACI) and Its Capability to Discriminate between General and Clinical Population). Psykhe, 15, 69-80. http://dx.doi.org/10.4067/S0718-22282006000200007

Vinet, E., \& Santacana, M. F. (2008). Chilean Norms for MACI: An Integration of Categorial and Dimensional Criteria. Terapia Psicológica, 26, 151-163. http://dx.doi.org/10.4067/S0718-48082008000200001

Vinet, E. V., Salvo, S., \& Forns, M. (2005). Adolescentes no consultantes en riesgo: Una evaluación a través del MACI (Non Consultants Adolescents at Risk: An Evaluation through MACI). Anuario de Psicología/The UB Journal of Psychology, 36, 83-97. http://www.raco.cat/index.php/AnuarioPsicologia/article/view/61808/76067

Wasserman, A. H. (2001). Exploring Normal Adolescent Sex Offenders: Investigating Moral Rigidity. Dissertation Abstracts International: Section B: The Sciences and Engineering, 61, 6122. 